\title{
Influence of natural ventilation due to buoyancy and heat transfer in the energy efficiency of a double skin facade building
}

\author{
E. Sanchez ${ }^{\text {a,* }}$, A. Rolando ${ }^{\text {a }}$, R. Sant ${ }^{\text {b }}$, L. Ayuso ${ }^{\text {b }}$ \\ a Departamento de Construccion y Tecnologia Arquitectonicas, Escuela Tecnica Superior de Arquitectura de Madrid, Universidad Politecnica de Madrid, Spain \\ b Departamento de Aeronaves y Vehiculos Espaciales, Escuela Tecnica Superior de Ingenieria Aeronautica y del Espacio, Universidad Politecnica de Madrid, Spain
}

\section{A R T I C L E I N F O}

\section{Article history:}

Received 28 September 2014

Revised 2 February 2016

Accepted 3 February 2016

Available online $\mathrm{xxxx}$

\section{Keywords:}

Double skin facades

Natural ventilation

Buoyancy effects

Heat transfer

Computational fluid dynamics (CFD)

Building energy efficiency

\begin{abstract}
A B S T R A C T
In recent years, the interest in double skin facades has increased because of esthetic reasons and for its use as passive system to save energy. Some authors have investigated their behavior related to thermal performance and energy efficiency compared to single skin facades but only considering the air cavity. The aim of this work is to identify a more efficient double glazed facade configuration that improves energy efficiency and indoor comfort conditions in buildings studying natural ventilation due to buoyancy-driven flow and heat transfer including solar radiation compared to a single skin facade. A simplified model was simulated using a computational fluid dynamics software to investigate the effects due to different cavity widths in winter and summer conditions with opened and closed vents and considering solar radiation or not. The main results obtained were that in winter closed vents is always efficient and ventilating is never beneficial. In summer closed vents is efficient in the absence of solar radiation and in its presence opened vents is favorable. Results showed the optimum air cavity width, and it was concluded that these double skin facades reduce the heating and cooling demands of a building, being more efficient compared to single skin facades.
\end{abstract}

(c) 2016 International Energy Initiative. Published by Elsevier Inc. All rights reserved.

\section{Introduction}

This study is the continuation of a previous work in which the state of the art in relation to the legislation, research and technology of envelope systems in architecture, taking into account natural ventilation and sealing to the penetration of wind driven rain, was analyzed (Sanchez and Rolando, 2014).

Double skin facades consist of two panes separated by an air cavity through which air flows in between. Generally, the outer pane is entirely made out of glass, while the inner pane may be partially opaque; but in this study, the two panes are made out of glass. This type of facade may incorporate vents to ventilate the air cavity when they are opened.

In recent years, the study and the interest in this type of envelopes have increased. They are often used in commercial buildings for esthetic reasons. The advantage of double skin facades is that they admit a high degree of daylight because of its large glazed area, but as a result, heat losses in winter and large increase in heat gains in summer can be achieved due to the solar energy transmittance to the interior and with the possible overheating of the building.

Double skin facades could be used as a passive system to improve thermal comfort conditions and building energy efficiency. These

\footnotetext{
* Corresponding author at: Departamento de Construccion y Tecnologia Arquitectonicas, Escuela Tecnica Superior de Arquitectura de Madrid, Universidad Politecnica de Madrid, Avda. Juan de Herrera, 4, 28040 Madrid, Spain. Tel.: + 34645200505.

E-mail address: edurne.sanchez.salcedo@alumnos.upm.es (E. Sanchez).
}

envelopes can be used as an efficient alternative for reducing the energy use in buildings.

The driving forces in the naturally ventilated double skin facades are thermal buoyancy, pressure differences due to wind or combined wind and buoyancy driven flow. In this paper, only buoyancy-driven flow is studied.

Natural convection due to buoyancy in closed rectangular cavities with differentially heated vertical walls has been studied experimentally as well as analytically and numerically extensively over the years (Korpela et al., 1973; Lartigue et al., 2000). The transition from laminar to turbulent flow, the flow characteristics, the physical phenomena that take place inside the cavity and the variables involved in the process were studied. Heat transfer in buoyancy-dominated flows is of fundamental importance in several architectural applications such as fenestration glazing cavities, cavities of ventilated facades and solar chimneys, among others.

In recent years, the behavior of the double skin facade has been investigated related to the thermal performance and energy efficiency of buildings compared to the single glazed facade system. Some authors utilized a CFD program to analyze the impacts of several parameters in double skin facades, such as orientation, wind and solar protection, depth of the cavity, glazing type, openings size, climatic conditions and solar radiation level, among others (Balocco, 2002; Faggembauu et al., 2003; Hien et al., 2005; Saelens et al., 2003; Zerefos, 2007; Gratia and De Herde, 2007). Other authors carried out full scale experiments to quantify the thermal performances and energy transmittance 


\begin{tabular}{|c|c|}
\hline \multicolumn{2}{|c|}{ Nomenclature } \\
\hline$A$ & aspect ratio (dimensionless) \\
\hline$C_{p}$ & specific heat $\left(\mathrm{Jkg}^{-1} \mathrm{~K}^{-1}\right)$ \\
\hline$g$ & gravitational acceleration $\left(\mathrm{m} / \mathrm{s}^{2}\right)$ \\
\hline$H$ & cavity height $(\mathrm{m})$ \\
\hline$h$ & average heat transfer coefficient $\left(\mathrm{Wm}^{-2} \mathrm{~K}^{-1}\right)$ \\
\hline$h_{e}$ & external heat transfer coefficient $\left(\mathrm{Wm}^{-2} \mathrm{~K}^{-1}\right.$ ) \\
\hline$h_{i}$ & internal heat transfer coefficient $\left(\mathrm{Wm}^{-2} \mathrm{~K}^{-1}\right)$ \\
\hline$h_{v}$ & air inlet and air outlet height $(\mathrm{m})$ \\
\hline$L$ & cavity width (m) \\
\hline$t_{p}$ & glass pane thickness (m) \\
\hline $\mathrm{Nu}$ & Nusselt number (dimensionless) \\
\hline $\operatorname{Pr}$ & Prandtl number (dimensionless) \\
\hline$Q$ & heat flux $\left(\mathrm{W} / \mathrm{m}^{2}\right)$ \\
\hline$Q_{r}$ & heat generation rate $\left(\mathrm{W} / \mathrm{m}^{3}\right)$ \\
\hline$Q_{s}$ & solar irradiance $\left(\mathrm{W} / \mathrm{m}^{2}\right)$ \\
\hline$q_{e}$ & $\begin{array}{l}\text { secondary heat transfer factor towards the outside } \\
\text { (dimensionless) }\end{array}$ \\
\hline$q_{i}$ & $\begin{array}{l}\text { secondary heat transfer factor towards the inside } \\
\text { (dimensionless) }\end{array}$ \\
\hline $\mathrm{Ra}_{\mathrm{L}}$ & Rayleigh number (dimensionless) \\
\hline$S_{\lambda}$ & $\begin{array}{l}\text { relative spectral distribution of the solar radiation } \\
\text { (dimensionless) }\end{array}$ \\
\hline$T$ & average temperature in the enclosure $(\mathrm{K})$ \\
\hline$T^{+}$ & $\begin{array}{l}\text { average dimensionless temperature in the enclosure } \\
\text { (dimensionless) }\end{array}$ \\
\hline$T^{*}$ & $\begin{array}{l}\text { dimensionless temperature in the air cavity } \\
\text { (dimensionless) }\end{array}$ \\
\hline$T_{c}$ & temperature of the cold pane $(\mathrm{K})$ \\
\hline$T_{h}$ & temperature of the hot pane $(\mathrm{K})$ \\
\hline$T_{\text {ref }}$ & reference temperature $(\mathrm{K})$ \\
\hline$x$ & cavity horizontal distance $(\mathrm{m})$ \\
\hline$X^{*}$ & cavity horizontal distance (dimensionless) \\
\hline$y$ & cavity vertical position (m) \\
\hline$Y^{*}$ & cavity vertical position (dimensionless) \\
\hline$\alpha$ & thermal diffusivity $\left(\mathrm{m}^{2} / \mathrm{s}\right)$ \\
\hline$\alpha_{e}$ & solar direct absorptance (dimensionless) \\
\hline$\alpha_{e 1}$ & $\begin{array}{l}\text { solar direct absorptance of the outer pane } \\
\text { (dimensionless) }\end{array}$ \\
\hline$\alpha_{e 2}$ & $\begin{array}{l}\text { solar direct absorptance of the second pane } \\
\text { (dimensionless) }\end{array}$ \\
\hline$\alpha_{1}(\lambda)$ & $\begin{array}{l}\text { spectral direct absorptance of the outer pane measured in } \\
\text { the direction of the incident radiation (dimensionless) }\end{array}$ \\
\hline$\alpha^{\prime}{ }_{1}(\lambda)$ & $\begin{array}{l}\text { spectral direct absorptance of the outer pane mea- } \\
\text { sured in the opposite direction to the incident radia- } \\
\text { tion (dimensionless) }\end{array}$ \\
\hline$\alpha_{2}(\lambda)$ & $\begin{array}{l}\text { spectral direct absorptance of the inner pane measured in } \\
\text { the direction of the incident radiation (dimensionless) }\end{array}$ \\
\hline$\beta$ & thermal expansion coefficient of air $\left(\mathrm{K}^{-1}\right)$ \\
\hline$\gamma$ & $\begin{array}{l}\text { total solar energy transmittance (solar factor) } \\
\text { (dimensionless) }\end{array}$ \\
\hline$\eta$ & energy efficiency index \\
\hline K & thermal conductivity $\left(\mathrm{Wm}^{-1} \mathrm{~K}^{-1}\right)$ \\
\hline$\Lambda$ & thermal conductance $\left(\mathrm{Wm}^{-2} \mathrm{~K}^{-1}\right)$ \\
\hline$\lambda$ & wavelength (m) \\
\hline$\Delta \lambda$ & wavelength interval (m) \\
\hline$\nu$ & kinematic viscosity $\left(\mathrm{m}^{2} / \mathrm{s}\right)$ \\
\hline$\rho$ & density $\left(\mathrm{kg} / \mathrm{m}^{3}\right)$ \\
\hline & solar direct reflectance (dimensionless) \\
\hline$\rho_{1}(\lambda)$ & $\begin{array}{l}\text { spectral reflectance of the outer pane measured in the di- } \\
\text { rection of incident radiation (dimensionless) }\end{array}$ \\
\hline$\rho^{\prime}{ }_{1}(\lambda)$ & $\begin{array}{l}\text { spectral reflectance of the outer pane measured in the } \\
\text { opposite direction of incident radiation (dimensionless) }\end{array}$ \\
\hline
\end{tabular}
$\rho_{2}(\lambda)$
spectral reflectance of the inner pane measured in the di- rection of incident radiation (dimensionless)
$\tau_{e}$
$\tau_{1}(\lambda)$
$\tau_{2}(\lambda)$ solar direct transmittance (dimensionless) spectral transmittance of the outer pane (dimensionless) spectral transmittance of the inner pane (dimensionless)

of single and double skin facades (Eicker et al., 2008; Kim et al., 2009). It was concluded that if double skin facades are designed carefully, they would exhibit a significantly better passive behavior than conventional glazed facades, and also would reduce energy consumption.

The goal of this paper is to study natural ventilation due to buoyancy and heat transfer in a double skin facade compared to a conventional glass facade. Other works only study the phenomena that take place in the air cavity, and many of them do not vary either the model geometry or the boundary conditions or take into account the solar radiation.

A CFD model, that includes conduction, convection and radiation is used to study the double skin facades behavior globally. The goal is to find the optimum air cavity width so as to reduce heating and cooling demands in the building, improving building energy efficiency.

The novelty is that a more extensive investigation is performed where the model is analyzed more broadly: outside environment, air cavity and inside the enclosure; varying the geometry: cavity width with closed and opened cavity vents; and under different conditions: winter and summer conditions with and without solar radiation. In all situations, the phenomena that take place from the point of view of heat transfer, temperature distribution, flow regimes and airflow characteristics, are studied and analyzed.

The aim is to achieve or identify a more efficient facade configuration that improves building energy efficiency to improve indoor comfort conditions.

\section{Geometry}

A simplified double skin facade model was used for the study. A 2D simulation was carried out and the flow was assumed steady state.

The basic geometry used in CFD simulations is illustrated in Figs. 1 and 2. It is an enclosure with a double skin facade facing south, composed by an inner facade, an air cavity and an outer facade.

The enclosure dimensions are $3 \mathrm{~m}$ high $(H)$ and $6 \mathrm{~m}$ wide $(2 H)$. The air cavity extends the whole height of the model. There is an air inlet $\left(h_{v}\right)$ near the bottom and an air outlet near the top of the section, both $6 \mathrm{~cm}$ high. The air cavity is completely closed off from the enclosure's interior. Different facade configurations are studied, therefore the air cavity width $(L)$ varies.

In order to study the various facade configurations under different conditions, the computational domain of the CFD simulation had to be extended to include part of the outside environment. In the study, the dimensions for the domain were $21 \mathrm{~m}$ wide and $10 \mathrm{~m}$ high.

Eight different cases were simulated with 29 facade configurations studied, which is a total of 116 cases. Winter and summer conditions were simulated, with closed and opened cavity vents and considering solar radiation or not. Every possible situation was considered, and several facade configurations were studied from the single skin facade to the double skin varying the cavity width with aspect ratios $(A)$ from 6 to 600 , where $A=H / L$, being $H$ the cavity height and $L$ the cavity width.

\section{Simulation software}

ANSYS Fluent ${ }^{\circledR}$ ( 14.0 version) was used to simulate the airflow and heat transfer. This commercial software has been previously validated in literature (Fuliotto et al., 2010). The air properties were assumed to be constant. The airflow inside the cavity was considered steady state and the pressure-based solver was used. 


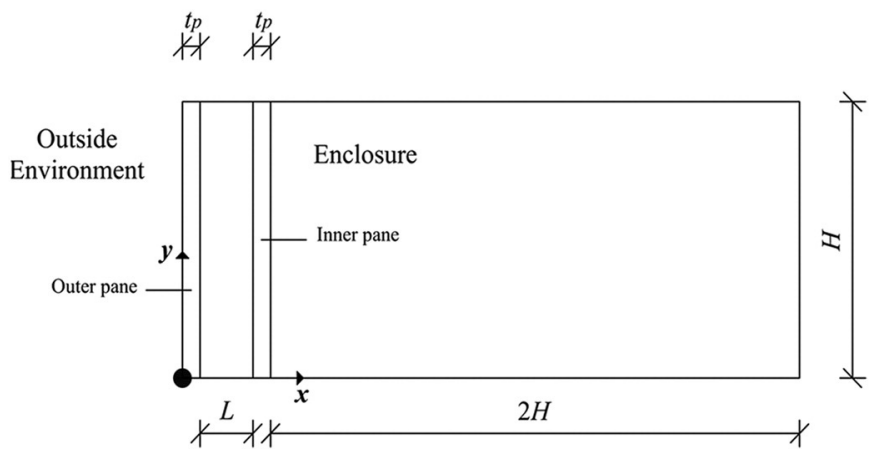

Fig. 1. Detail of the air cavity with closed vents. Measurements in meters (m).

The Incompressible-Ideal-Gas model was used to approximate the relationship between density and temperature change (thermal buoyancy). Li et al. (2007), presented a study in which a model was calculated by theoretical analysis and by CFD simulation using the Boussinesq model. The results obtained in their study were compared with those obtained by the Incompressible-Ideal-Gas model, and it was concluded that this model showed more accurate predictions than the Boussinesq model that is commonly used.

The CFD model used in this work is based on the Reynolds-Averaged Navier Stokes (RANS) equations. The continuity, momentum and energy equations are solved with RNG $\mathrm{k}-\varepsilon$ (2 equations) turbulence model, which was recommended for building simulation (Yakhot et al., 1992), with non-equilibrium wall treatment and full buoyancy effects. Prandtl number $(\operatorname{Pr})$ is 0.709 and is assumed constant. Ratio of kinematic viscosity $(v)$ and thermal diffusivity $(\alpha)$ of air are also constant. The governing equations are discretized with finite volume methods.

The coupling between the governing equations was made by means of the SIMPLE scheme, least squares cell based solver was used, and body force weighted was selected as method for the pressure discretization. Second order approximations were used for the solution of differential equations.

A non-uniform structured mesh was used in the simulations. The mesh was refined near the cavity walls, with dense cell distribution inside the air cavity and near the glass panes. The solution was checked with different grids.

The glass panes were modeled and meshed to be $6 \mathrm{~mm}$ thick $\left(t_{p}\right)$, so there were several cells between both glass faces. Fluent considered the glass panes as solid, so the physical properties of glass could be set as material input. Thus, the physical phenomenon that take place inside the glass and in the surrounding fluid could be studied, and better predictions could be obtained.

\section{Boundary conditions}

The boundary conditions for the outside environment are: pressure inlet for the lateral boundaries, pressure outlet for the upper boundary, and adiabatic wall for the outside ground. The outside temperature is

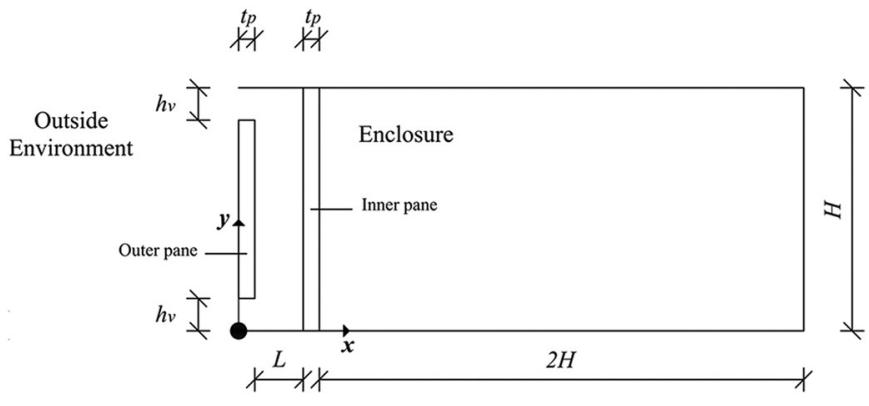

Fig. 2. Detail of the air cavity with opened vents. Measurements in meters (m). specified as $4{ }^{\circ} \mathrm{C}(277 \mathrm{~K})$ for winter conditions and as $32{ }^{\circ} \mathrm{C}(305 \mathrm{~K})$ for summer conditions, average temperatures in central Spain.

For winter conditions a heat source uniformly distributed in the enclosure's floor with a heat flux of $22 \mathrm{~W} / \mathrm{m}^{2}$ was specified. For summer conditions a heat source uniformly distributed in the enclosure's ceiling with a negative heat flux of $-4.6 \mathrm{~W} / \mathrm{m}^{2}$ was specified.

The heat flux values were calculated for a single facade. For winter conditions, the heat necessary to be provided in order to keep the enclosure temperature at $20^{\circ} \mathrm{C}(293 \mathrm{~K})$ was calculated. For summer conditions, the heat necessary to be removed in order to keep the enclosure temperature at $26{ }^{\circ} \mathrm{C}(299 \mathrm{~K})$ was calculated. These temperatures were considered the comfort temperatures for each condition.

All the other enclosure walls were regarded as adiabatic.

The vertical glass surfaces were specified as walls with no slip boundary conditions. They were coupled to enable the conduction heat transfer. All the other horizontal glass surfaces were considered as adiabatic.

\section{Model validation}

As explained in section 3, the model was validated using the Li et al. calculated data in which buoyancy-driven natural ventilation of a room with large lower and higher level openings is investigated by both theoretical analysis and CFD simulation. This investigation was chosen as a reference case for the model validation because it was a case of natural convection with a basic geometry and in a similar environment to this study. As explained above, the use of the Incompressible-IdealGas model was validated against the Boussinesq model and it gave better predictions.

To verify that the model was valid for double skin facades as well, the He's calculated data (He et al., 2011) were used. In this work a double skin facade was simulated with CFD techniques to study natural ventilation due to buoyancy and heat transfer. A simplified double skin window model was used based on one designed for a building in Hangzhou (China). It consists of a single glass pane on the outside and a double glazing pane on the inside separated by an air cavity $0.20 \mathrm{~m}$ wide. For the purpose of validation, the same model was simulated under winter conditions with closed vents and without solar radiation. Good agreement was obtained in the results.

\section{The decoupling approach}

In the present study the convective and conductive heat flow was solved by CFD and the solar radiation was calculated independently. Solar absorption was represented by heat sources uniformly distributed within the glass panes. The enclosure gained heat from the solar radiation in two ways: transmission and heat convection from the glass.

The CFD software provides several methods to include solar radiation in the model, but they are complex and have a demanding computing time when radiation heat transfer is included. On the other hand, accurately modeling the solar radiation is not the aim of this study. Therefore, some researchers investigated other methods to calculate the solar radiation. Several authors used a separate program to solve the radiation heat transfer (Pappas and Zhai, 2008), some solved the convective and radiation heat transfer at the same time (Manz, 2004), and others calculated the heat absorbed by each glass pane according to the standards (Batchelor, 1953).

So to simplify the solar radiation model and to reduce the computing time, the heat flow due to solar radiation was represented by a heat source uniformly distributed and perpendicular to the pane surface. The heat flux was calculated knowing the solar irradiance and taking into account the optical and thermal properties of each pane. 
The optical properties express the behavior of the glass to daylight and radiation. Among the most important are the transmittance, reflectance and absorptance. To follow, the behavior of the solar radiation on a glass pane is explained, see Fig. 3. When solar radiation is incident on a glass pane, several phenomena take place. A part of the solar radiation is reflected instantaneously $\left(\rho_{e}\right)$, so it neither penetrates glass nor heats it. Another part of the solar radiation penetrates the glass but is absorbed internally $\left(\alpha_{e}\right)$, promoting its heating. Part of this absorbed energy, is retransmitted inwards $\left(q_{i}\right)$ and another part outwards $\left(q_{e}\right)$ in varying amounts, depending on the glass characteristics and on the indoor or outdoor temperature. Finally, the part of the radiation that is neither reflected nor absorbed, goes through the glass and is transmitted directly inside $\left(\tau_{e}\right)$.

The total energy passing through the glass is called solar factor, and is the sum of the solar energy that enters through direct transmission $\left(\tau_{e}\right)$ and the energy released by the glazing to the inside after its heating by energy absorption $\left(q_{i}\right)$.

Through an optical analysis it was possible to determine transmitted, reflected and absorbed components of solar radiation. Finally, the absorbed component could be used as input into the thermal analysis.

A soda lime glass, whose physical properties were taken from the European Standard 10456:2012 (EN ISO 10456:2012, 2012), has been used to study. The soda lime glass characteristics are shown in Table 1.

The solar irradiance $Q_{s}$, used to calculate the heat generation rate $Q_{\text {r }}$, was based on the climatic database developed by the German Passive House Institute (Guía de la herramienta Passivhaus, 2012) as a climate reference for Central Europe.

Based on the observation data, $101 \mathrm{kWh} / \mathrm{m}^{2}$ per month for January global radiation was taken as the solar irradiance for winter conditions; and $117 \mathrm{kWh} / \mathrm{m}^{2}$ per month for August global radiation was taken as the solar irradiance for summer conditions. These global radiation values are the irradiance on the south facade and taking into account the climatic data of central Spain.

According to the European Standard EN 410:2011 (EN 410:2011, 2011), the total solar energy transmittance $\gamma$ is defined as the portion of incoming solar energy transmitted to the enclosure behind the glazing. It is calculated as the sum of the solar direct transmittance $\tau_{e}$ and the secondary heat transfer factor $q_{i}$ towards the inside.

$\gamma=\tau_{e}+q_{i}$
The incident solar radiant flux is divided into three portions: transmitted $\left(\tau_{e}\right)$, reflected $\left(\rho_{e}\right)$, and absorbed $\left(\alpha_{e}\right)$. The relationship between the three characteristics is:

$\tau_{e}+\rho_{e}+\alpha_{e}=1$

The absorbed part is divided into two parts $q_{i}$ and $q_{e}$ that are energy transferred to the inside and outside respectively:

$\alpha_{e}=q_{i}+q_{e}$.

For single glazing, $q_{i}$ is calculated by:

$q_{i}=\alpha_{e} \frac{h_{i}}{h_{e}+h_{i}}$

$h_{e}$ and $h_{i}$ are the heat transfer coefficients towards the outside and towards the inside respectively. According to the European Standard EN 673:2011 (EN 673: 2011, 2011), $h_{e}=25 \mathrm{Wm}^{-2} \mathrm{~K}^{-1}$ and $h_{i}=7.7$ $\mathrm{Wm}^{-2} \mathrm{~K}^{-1}$. See Table 1 . After applying these formulas for single glazing, it was concluded that the absorption of the glass pane was $\alpha_{e}=0.11$.

For double glazing, $q_{i}$ is calculated by:

$q_{i}=\frac{\frac{\alpha_{e 1}+\alpha_{e 2}}{h_{e}}+\frac{\alpha_{e 2}}{\Lambda}}{\frac{1}{h_{i}}+\frac{1}{h_{e}}+\frac{1}{\Lambda}}$

where $\alpha_{e 1}$ and $\alpha_{e 2}$ are the solar direct absorptance of the outer pane and the second pane within the double glazing respectively, and $\Lambda$ is the thermal conductance between the outer surface and the innermost surface of the double glazing.

$\alpha_{e 1}=\frac{\sum_{\lambda=300 \mathrm{~nm}}^{2500 \mathrm{~nm}} S_{\lambda}\left\{\alpha_{1}(\lambda)+\frac{\alpha^{\prime}{ }_{1}(\lambda) \tau_{1}(\lambda) \rho_{2}(\lambda)}{1-\rho^{\prime}{ }_{1}(\lambda) \rho_{2}(\lambda)}\right\} \Delta \lambda}{\sum_{\lambda=300 \mathrm{~nm}}^{2500 \mathrm{~nm}} S_{\lambda} \Delta \lambda}$

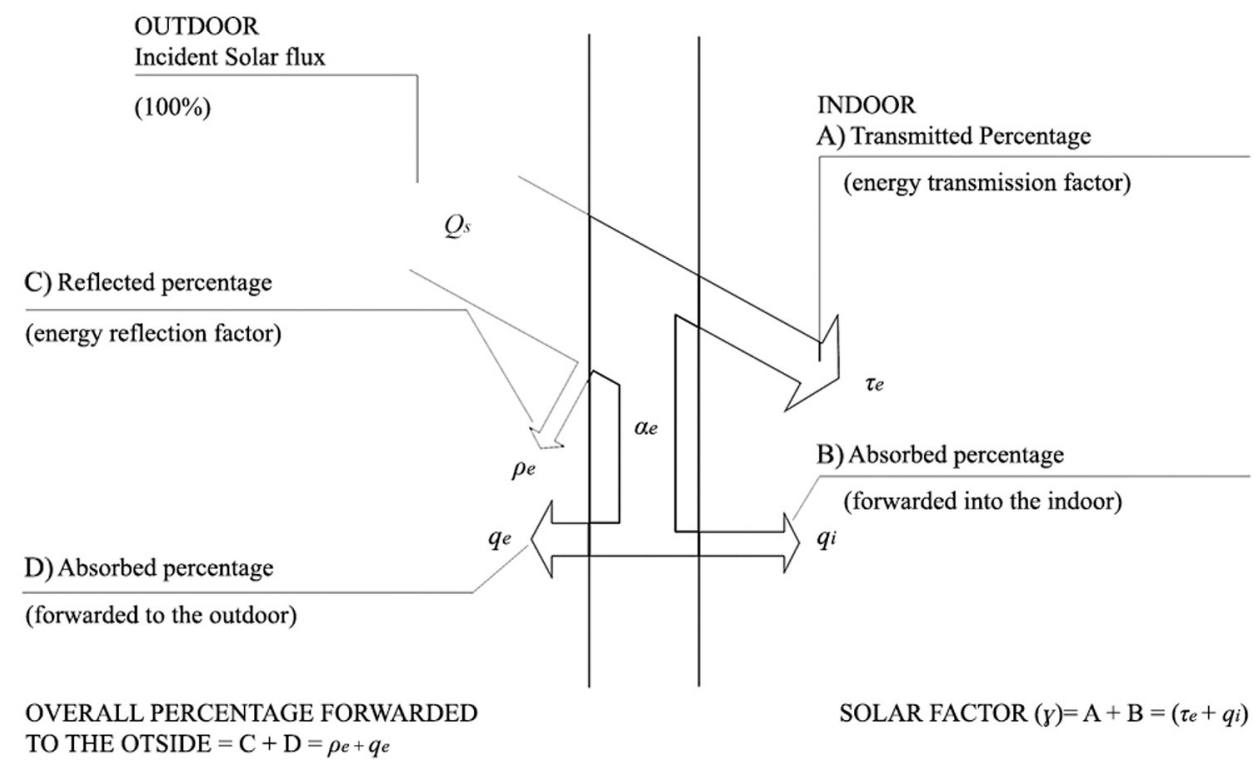

Fig. 3. Behavior of the solar radiation on a glass pane. 
Table 1

Physical, optical and thermal properties of the glass panes.

\begin{tabular}{|c|c|c|c|c|}
\hline Properties & $\begin{array}{l}\text { UNE-EN ISO } \\
10456: 2012\end{array}$ & $\begin{array}{l}\text { Single pane }(6 \mathrm{~mm}) \\
\text { UNE-EN 410:2011 }\end{array}$ & $\begin{array}{l}\text { Double pane }(6+L+6) \mathrm{mm} \\
\text { UNE-EN 410:2011 }\end{array}$ & $\begin{array}{l}\text { UNE-EN } \\
673: 2011\end{array}$ \\
\hline Density, $\rho\left(\mathrm{kg} / \mathrm{m}^{3}\right)$ & 2500 & & & \\
\hline Specific heat, $C_{p}(\mathrm{~J} / \mathrm{kg} \mathrm{K})$ & 750 & & & \\
\hline Thermal conductivity, $K(\mathrm{~W} / \mathrm{m} \mathrm{K})$ & 1 & & & \\
\hline Transmittance, $\tau_{e}(\%)$ & & 82 & 68 & \\
\hline Reflectance, $\rho_{e}(\%)$ & & 7 & 13 & \\
\hline Heat transfer coefficient towards the outside, $h_{e}\left(\mathrm{Wm}^{-2} \mathrm{~K}^{-1}\right)$ & & & & 25 \\
\hline Heat transfer coefficient towards the inside, $h_{i}\left(\mathrm{Wm}^{-2} \mathrm{~K}^{-1}\right)$ & & & & 7.7 \\
\hline
\end{tabular}

$\alpha_{e 2}=\frac{\sum_{\lambda=300 \mathrm{~nm}}^{2500 \mathrm{~nm}} S_{\lambda}\left\{\frac{\alpha_{2}(\lambda) \tau_{1}(\lambda)}{1-\rho^{\prime}(\lambda) \rho_{2}(\lambda)}\right\} \Delta \lambda}{\sum_{\lambda=300 \mathrm{~nm}}^{2500 \mathrm{~nm}} S_{\lambda} \Delta \lambda}$

where $\alpha_{1}(\lambda)$ and $\alpha_{2}(\lambda)$ are the spectral direct absorptance of the outer and inner pane respectively measured in the direction of the incident radiation; $\alpha^{\prime}{ }_{1}(\lambda)$ is the spectral direct absorptance of the outer pane measured in the opposite direction to the incident radiation; $\tau_{1}(\lambda)$ and $\tau_{2}(\lambda)$ are the spectral transmittance of the outer and inner pane respectively; $\rho_{1}(\lambda)$ and $\rho_{2}(\lambda)$ are the spectral reflectance of the outer and inner pane respectively measured in the direction of incident radiation; $\rho^{\prime}{ }_{1}(\lambda)$ is the spectral reflectance of the outer pane measured in the opposite direction of incident radiation; $\lambda$ is the wavelength; $S_{\lambda}$ is the relative spectral distribution of the solar radiation; and $\Delta \lambda$ is the wavelength interval.

After applying these formulas for double glazing, it was concluded that the absorption of the outer glass pane was $\alpha_{e 1}=0.11$ and the absorption of the inner glass pane was $\alpha_{e 2}=0.08$.

Once the solar absorption of each glass pane was calculated, they were multiplied by the solar irradiance and the heat generation rate was obtained. This value is the heat source that represents the solar absorption according to the solar irradiance of each condition.

The corresponding value for each case was introduced in the thermal boundary conditions of the CFD software. The glass panes were coupled to consider the effect of the conduction between the air and the glass panes.

\section{Results}

After simulating all the facade configurations under different boundary conditions, a wide range of relevant parameters are analyzed in this study. The results obtained are presented by using dimensionless graphs. Theory shows that to derive general expressions based on dimension analysis for heat transfer and air flow in ventilation cavities, dimensionless numbers can be introduced including Nusselt number $(\mathrm{Nu})$ for the heat transfer rate and Rayleigh number $\left(\mathrm{Ra}_{\mathrm{L}}\right)$ associated with the cavity size and boundary conditions. Etheridge (2002) pointed out a number of benefits of using non-dimensional graphs generated from sophisticated numerical models for natural ventilation design.

\section{Winter conditions}

\section{Average temperature in the enclosure}

Single skin facade was taken as the reference case with which to compare the results obtained, and the heat needed to be provided to keep the enclosure temperature at $20{ }^{\circ} \mathrm{C}$ (comfort temperature in winter conditions) was calculated for the cases with and without solar radiation respectively. The winter scenario was simulated with a floor heat flux of $17.9 \mathrm{~W} / \mathrm{m}^{2}$, for the cases with solar radiation, and of $22 \mathrm{~W} / \mathrm{m}^{2}$ for the cases without it.
Fig. 4 represents the average dimensionless temperature $T^{+}=\left(T-T_{r e f}\right) / T_{\text {ref }}$ in the enclosure in relation to the cavity aspect ratio $A$, ratio between the cavity height and the cavity width, in the winter scenario and under different conditions; where $T$ is the average temperature in the enclosure; and $T_{\text {ref }}$ is the reference temperature, the average temperature in the enclosure in the case of a single glazed facade.

From the point of view of the cavity aspect ratio, the following results were obtained:

- In the case of closed vents, both solar radiation and without it, three distinct sections can be observed:

- For $A<15$, a slight decrease in temperature is observed. This is because the decrease of the cavity width results in a decrease of the thermal resistance of the system. This is often referred to as the buffer or conservatory effect. In the presence of solar radiation, the effect is higher, decreases the transmission losses and even provides gains. Thus, it is demonstrated that the air cavity continues insulating thermally. In this section, as explained in the section Temperature distribution in the air cavity, the boundary layer regime (convection) dominates.

- For $15 \leq A \leq 80$, the temperature remains constant or without major variations, the transition regime dominates.

- For $A>80$, the average temperature in the enclosure lowers, the conduction regime dominates.

- For the opened vents situation, both with solar radiation and without it, three distinct sections can also be observed:

- For $A<60$, the temperature remains constant, convection dominates.

- For $60 \leq A \leq 300$, the average temperature in the enclosure increases and the airflow is uniform.

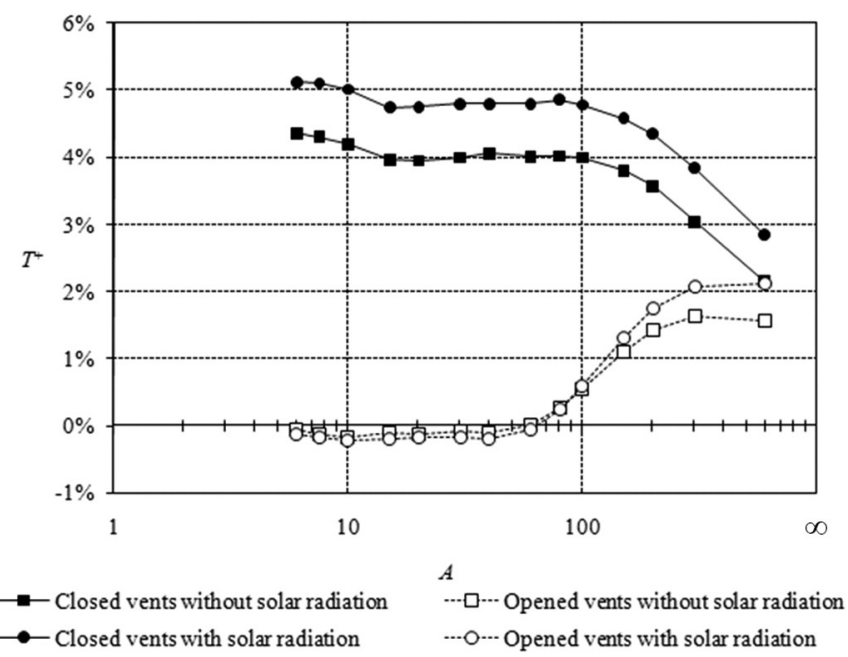

Fig. 4. Average temperature in the enclosure in winter scenario. 
- For $A>300$, the average temperature in the enclosure lowers, the conduction regime dominates and the airflow is uniform.

Temperature distribution in the air cavity

This study performed a comprehensive analysis on the relationship between airflow rate and the temperature difference between the glass panes for different cavity aspect ratios and environment conditions. The two glass panes of the double skin facade separate two environments that are at different temperatures, therefore, heat transfer from the hot pane to the cold pane occurs. The heat exchange through the facade is produced according to three modes of propagation: conduction, convection and radiation.

The mode of heat exchange depends on the Rayleigh number $\left(\operatorname{Ra}_{\mathrm{L}}\right)$, which is calculated as a function of the cavity width and the temperature difference between the hot pane and the cold pane.

$\mathrm{Ra}_{\mathrm{L}}=\frac{g L^{3} \beta\left(T_{h}-T_{c}\right)}{\nu \alpha}$

where $g$ is the acceleration of gravity; $L$ the width of the air cavity; $\beta$ the thermal expansion coefficient of air; $T_{h}$ the temperature of the hot pane; and $T_{c}$ the temperature of the cold pane.

According to previous investigations on natural convection and heat transfer in enclosed air cavities (Yin et al., 1978), the flow regime can be classified in conduction, transition and boundary layer regime, depending on the Rayleigh number and the aspect ratio of the air cavity.

In the study, aspect ratios from 6 to 600 were studied and Rayleigh numbers (based on the cavity width) between 10 and $10^{8}$ were obtained.

Fig. 5 shows the dimensionless temperature distribution $T^{*}=(T-$ $\left.T_{c}\right) /\left(T_{h}-T_{c}\right)$, as a function of the distance $\left(\mathrm{X}^{*}=\mathrm{x} / \mathrm{H}\right)$, from the hot wall to the cold wall of the cavity for the aspect ratios of 150,30 and 7.5 respectively. The dimensionless temperature profile in the air cavity for a given horizontal section for different dimensionless vertical positions $\left(\mathrm{Y}^{*}=\mathrm{y} / \mathrm{H}\right)$ are plotted for $\mathrm{Y}^{*}=0.0065 ; 0.0374 ; 0.5$; 0.9681 ; and 0.9935 .

The temperature profiles were validated and verified with the ones obtained by Xamán (Xamán et al., 2005) in which turbulent natural convection flow in a two-dimensional tall rectangular cavity was investigated numerically for aspect ratios of 20, 40 and 80 .

In the case of the Rayleigh numbers under $10^{4}$, see Fig. 5, the temperature distribution in the cavity is linear. It indicates that the heat is transported mainly by conduction through the central core of the cavity. This linear temperature profile is called the conduction regime.

For Rayleigh numbers between $10^{4}$ and $10^{7}$, the heat is transported by convection, and that in the central core of the cavity the heat is transported by conduction. Because of the Rayleigh number increase, convective heat transport gains in importance and the linear temperature profile disappears. This flow regime is called transition regime.

For Rayleigh numbers greater than $10^{7}$, the heat is transported mainly by convection from the hot to the cold pane. In this case, high horizontal temperature gradients occur near the wall surfaces, but temperature is almost constant in the central core of the cavity. This flow field regime is called the boundary layer regime because it is dominated by the air circulation through the two vertical surfaces.

In the closed cavity situation, the following flow regimes are given in terms of the aspect ratio and the Rayleigh number:

- Boundary layer regime, up to $A=15, \mathrm{Ra}_{\mathrm{L}} \geq 10^{7}$

- Transition regime, from $A=15$ to $A=80,10^{4}<\operatorname{Ra}_{\mathrm{L}}<10^{7}$

- Conduction regime, from $A=80, \mathrm{Ra}_{\mathrm{L}} \leq 10^{4}$

Fig. 5. Temperature profile in the air cavity for a given horizontal section for different vertical positions: $A=150$, conduction regime; $A=30$, transition regime; and $A=7.5$, boundary layer regime.
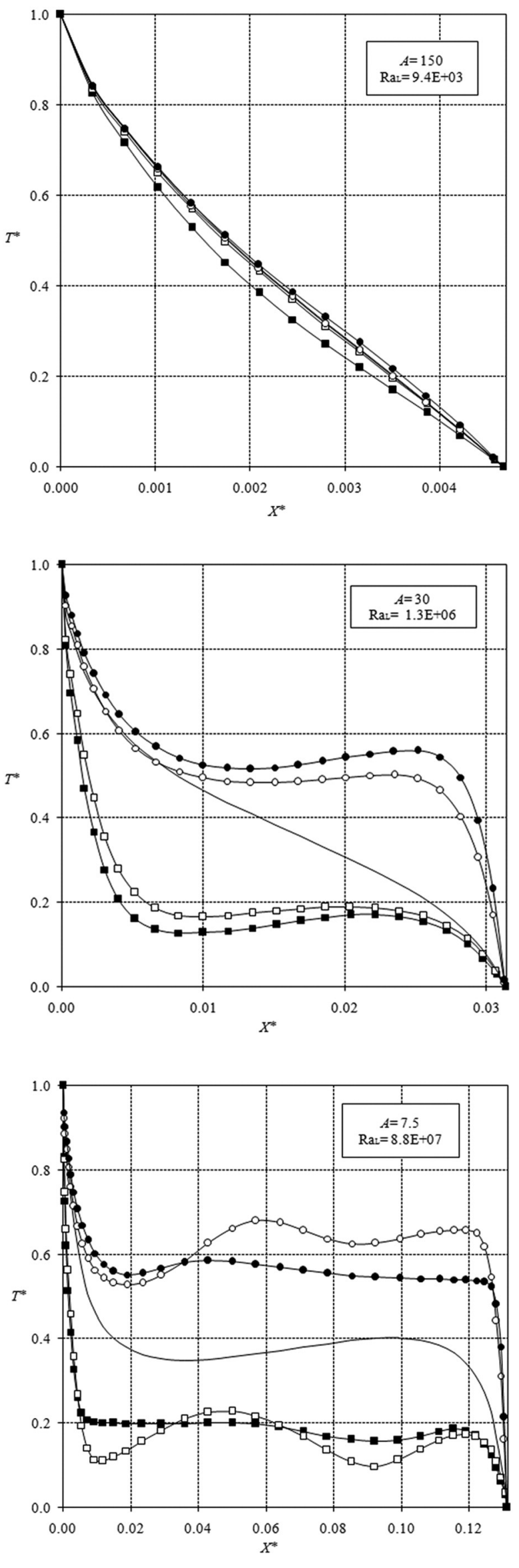

$\rightarrow-\mathrm{Y}^{*}=0.0195 \multimap \square-\mathrm{Y}^{*}=0.1122-\mathrm{Y}^{*}=1.5 \multimap \mathrm{Y}^{*}=2.9043 \rightarrow \mathrm{Y}^{*}=2.9805$ 
In all situations, the average temperature in the air cavity is always lower than the average temperature in the enclosure.

\section{Heat transfer}

The Nusselt number ( $\mathrm{Nu}$ ) is a dimensionless number that measures the ratio of convective heat transfer and conductive heat transfer across the air cavity.

$\mathrm{Nu}=\frac{h L}{K}$

where $h$ is the average heat transfer coefficient across the air cavity; $L$ the width of the air cavity; and $K$ the thermal conductivity of air.

The heat transfer rate and the correlations obtained are shown in Fig. 6, and it is analyzed in terms of the following independent parameters: Rayleigh number and cavity aspect ratio. When considering natural convection heat transfer within cavities, literature, in general, states that heat transfer can be determined in functional notation as: $\mathrm{Nu}=f\left(\mathrm{Ra}_{\mathrm{L}}, \operatorname{Pr}, A\right)$. The Prandtl number is considered constant. Thus, the functional relationship is reduced as: $\mathrm{Nu}=f\left(\mathrm{Ra}_{\mathrm{L}}, A\right)$.

It was observed that the heat transfer rate obtained agreed well with several correlations of the convective Nusselt numbers reported in the literature which were similar to the expression $\mathrm{Nu}=\mathrm{k} 1 \mathrm{Ra}_{\mathrm{L}}^{\mathrm{k} 2}$, where $\mathrm{k} 1$ and $\mathrm{k} 2$ are constants that depend on the value of $A$ and on the range of $\mathrm{Ra}_{\mathrm{L}}$ studied, and where $\mathrm{k} 1<1$ and $\mathrm{k} 2$ on the order of 0.3 as the results reported from Wright (Wright, 1996) and Elsherbiny (ElSherbiny et al., 1982).

It can be observed that the Nusselt number increases and with the Rayleigh number.

\section{Optimum air cavity width}

In this study, different double skin facade configurations, varying the air cavity width, under different boundary conditions were studied. After analyzing the results obtained from the point of view of the average temperature in the enclosure, the average temperature in the air cavity, the temperature distribution and the heat transfer rate; it was concluded that the optimum air cavity width was on the order of the aspect ratio $A=30$ because in the winter scenario lower values did not improve the insulation for the closed vents situation, which is the most efficient, and higher values insulated significantly less. The value of $A=30$ is also accurate for the summer scenario as explained below in the section Optimum air cavity width. Furthermore, this $A$ supposed a moderate air cavity width.

The heat flux necessary to be provided in the case of $A=30$, so that the enclosure temperature is $20^{\circ} \mathrm{C}$, was calculated for each situation. Fig. 7 shows the results obtained.

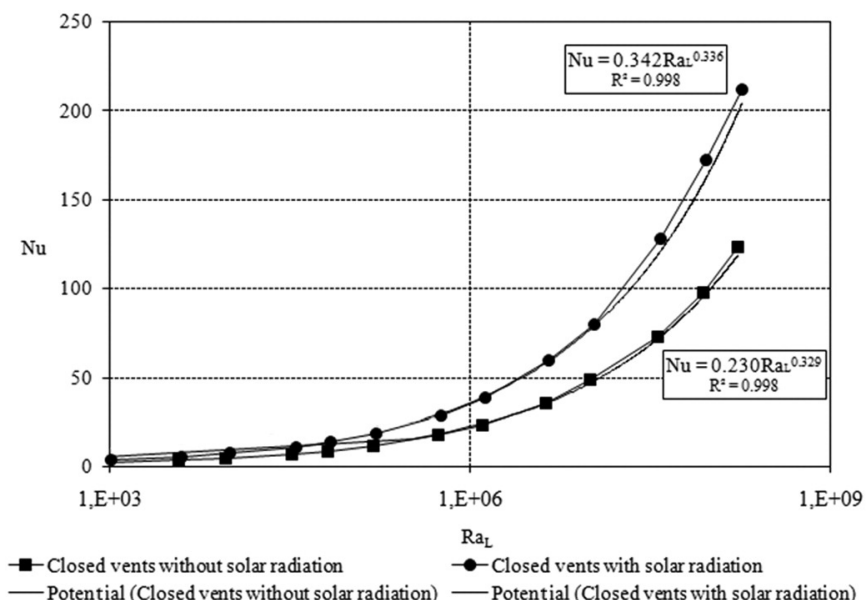

Fig. 6. Heat transfer rate in winter scenario.

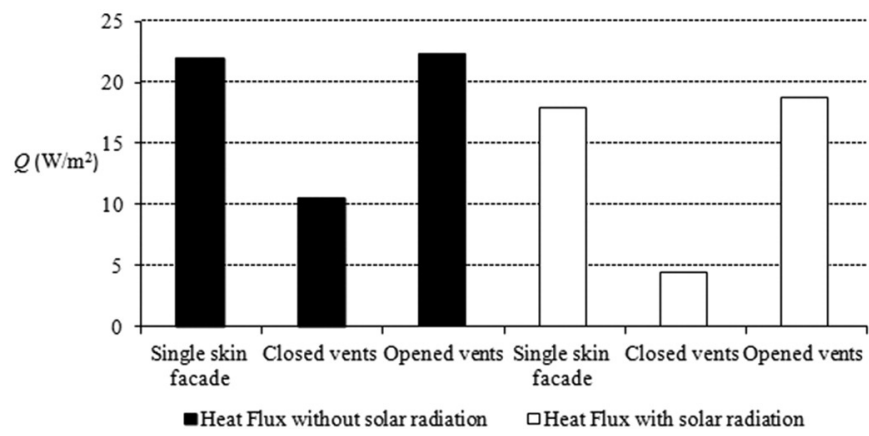

Fig. 7. Heat flux for single skin and $A=30$ to keep the enclosure temperature at $20{ }^{\circ} \mathrm{C}$ in winter.

On one hand, the cases with solar radiation are grouped, and on the other hand, those without solar radiation. It is observed that in both situations, the heat flux needed to be provided for a double skin system is lower than that for a single skin system, except for the cases of opened vents.

\section{Summer conditions}

\section{Average temperature in the enclosure}

Single skin facade was taken as the reference case with which to compare the results obtained, and the heat needed to be removed to keep the enclosure temperature at $26{ }^{\circ} \mathrm{C}$ (comfort temperature in summer conditions) was calculated for the cases with and without solar radiation respectively. The summer scenario was simulated with a ceiling heat flux of $-10.5 \mathrm{~W} / \mathrm{m}^{2}$, for the cases with solar radiation, and of $-4.6 \mathrm{~W} / \mathrm{m}^{2}$ for the cases without it.

Fig. 8 represents the average dimensionless temperature $T^{+}$in the enclosure in relation to the cavity aspect ratio $A$ in the summer scenario and under different conditions.

On one hand, from the point of view of the cavity aspect ratio, the following results were obtained:

For the closed vents situation:

- Without solar radiation:

- For $A<15$, the average temperature remains constant with a minimum increase in temperature. In this section, the boundary layer regime dominates.

- For $15 \leq A \leq 80$, the temperature remains constant and the transition regime dominates.

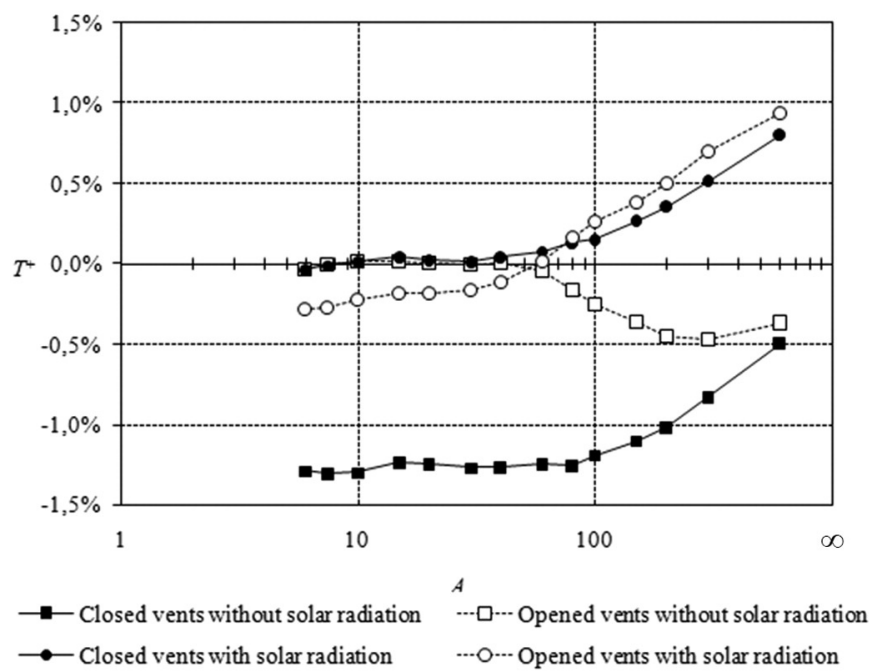

Fig. 8. Average temperature in the enclosure in summer scenario. 
- For $A>80$, the average temperature in the enclosure increases, the conduction regime dominates.

- With solar radiation:

- For $A<15$, a slight increase in temperature is observed. In this section, the boundary layer regime dominates.

- For $15 \leq A \leq 60$, the temperature remains constant and the transition regime dominates.

- For $A>60$, the average temperature in the enclosure rises and the conduction regime dominates.

In the assumption of opened vents:

- Without solar radiation:

- For $A<40$, the temperature remains constant to almost the reference temperature that is obtained with the single skin facade system.

- For $40 \leq A \leq 200$, the average temperature in the enclosure decreases.

- For $A>200$, the temperature increases slightly, but always below the reference temperature.

- With solar radiation:

- For $6 \leq A \leq 600$, the average temperature in the enclosure always increases. This fact is due to the increase of the stack effect in the presence of solar radiation. Double skin facade with purely stack effect is effective enough to extract solar heat gain inside the facade cavity and maintain lower internal surface temperature. The external surface temperature of double glazed facade is very high because of the characteristic of heat absorption.

\section{Temperature distribution in the air cavity}

As explained above, the flow regime can be classified in conduction, transition and boundary layer regime, depending on the Rayleigh number and the cavity aspect ratio.

In all situations, whether solar radiation is present or not as well as whether vents are opened or closed, the average temperature in the air cavity is always higher than the average temperature in the enclosure. The average temperature in the air cavity increases by absorbed solar radiation.

In the closed cavity situation without solar radiation, the following flow regimes are given:

- Boundary layer regime, up to $A=15, \operatorname{Ra}_{\mathrm{L}} \geq 10^{7}$

- Transition regime, from $A=60$ to $A=15,10^{4}<\mathrm{Ra}_{\mathrm{L}}<10^{7}$

- Conduction regime, from $A=60, \operatorname{Ra}_{\mathrm{L}} \leq 10^{4}$

In the closed cavity situation with solar radiation, the following flow regimes are obtained:

- Boundary layer regime, up to $A=15, \mathrm{Ra}_{\mathrm{L}} \geq 10^{7}$

- Transition regime, from $A=40$ to $A=15,10^{4}<\mathrm{Ra}_{\mathrm{L}}<10^{7}$

- Conduction regime, from $A=40, \operatorname{Ra}_{\mathrm{L}} \leq 10^{4}$

\section{Heat transfer}

Fig. 9 represents the heat transfer rate in closed air cavities and the correlations obtained for the cases with solar radiation and without it, in a summer scenario.

The heat transfer rate obtained was compared with several correlations of the convective Nusselt numbers reported in the literature and it was observed that they agreed as well with the results obtained by Wright and Elserbiny as explained above in the section Heat transfer.

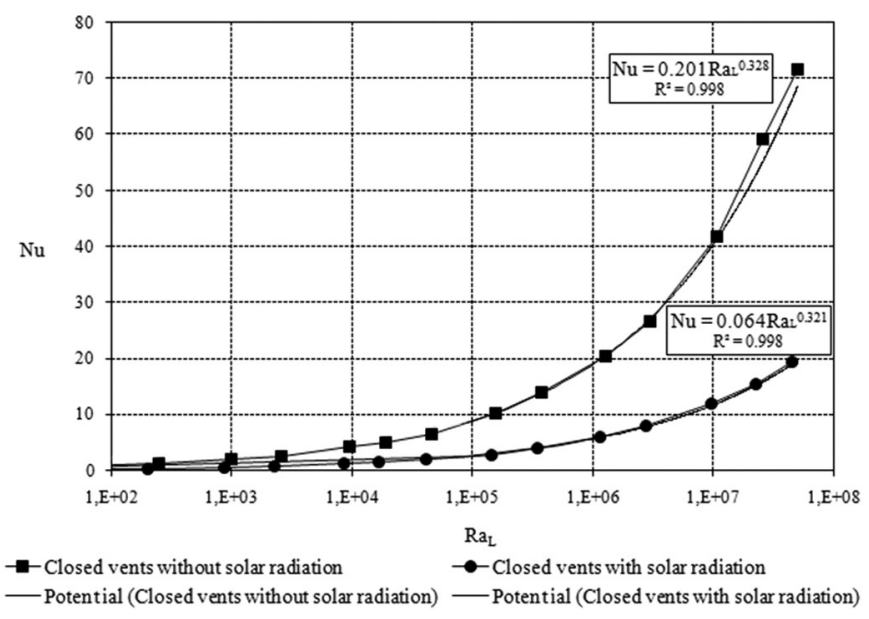

Fig. 9. Heat transfer rate in summer scenario.

Optimum air cavity width

It was concluded that the optimum air cavity width was on the order of the aspect ratio $A=30$ because in the summer scenario from $A=30$ it began to insulate less even in the closed vents situation.

The heat flux necessary to be removed in the case of $A=30$, so that the enclosure temperature is $26^{\circ} \mathrm{C}$, was calculated for each situation. Fig. 10 illustrates the results obtained.

On one hand, the cases with solar radiation are grouped, and on the other hand, those without solar radiation. It is observed that in the absence of solar radiation, the heat flux needed to be removed for a double skin system is higher than that for a single skin system, except in the case of closed vents. And in the presence of solar radiation it is just the opposite; the heat flux needed to be removed for a double skin system is higher than that for a single skin system, except in the case of opened vents.

\section{Energy efficiency analysis}

In this paper, the thermal behavior due to buoyancy of an enclosure located in central Spain with and without double skin facade is compared. The aim is to achieve or identify a more efficient facade configuration that improves the building energy efficiency to improve indoor comfort conditions. A cavity width corresponding to $A=30$ has been used, and below, the energy efficiency index in all scenarios is analyzed and discussed.

Figs. 11 and 12 represent the energy efficiency index in winter and summer scenarios respectively. They show the energy saving or the increased energy use for each situation. To do this, the heat flux required to be provided or removed, so that the enclosure remained within

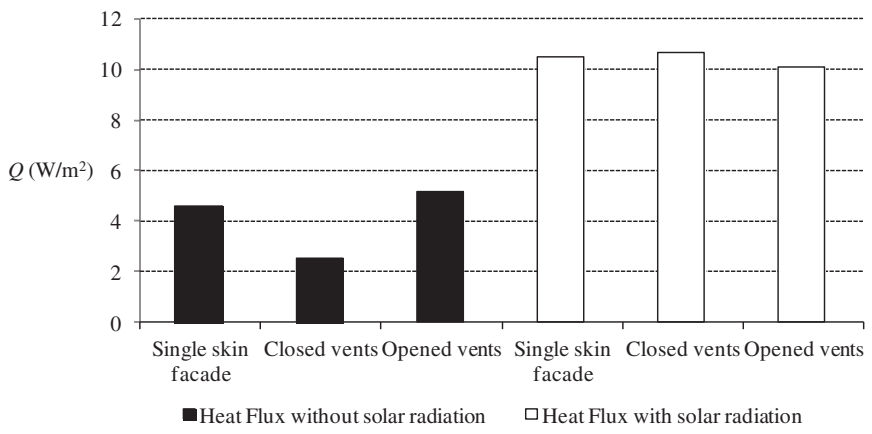

Fig. 10. Heat flux for single skin and $A=30$ to keep the enclosure temperature at $26^{\circ} \mathrm{C}$ in summer. 


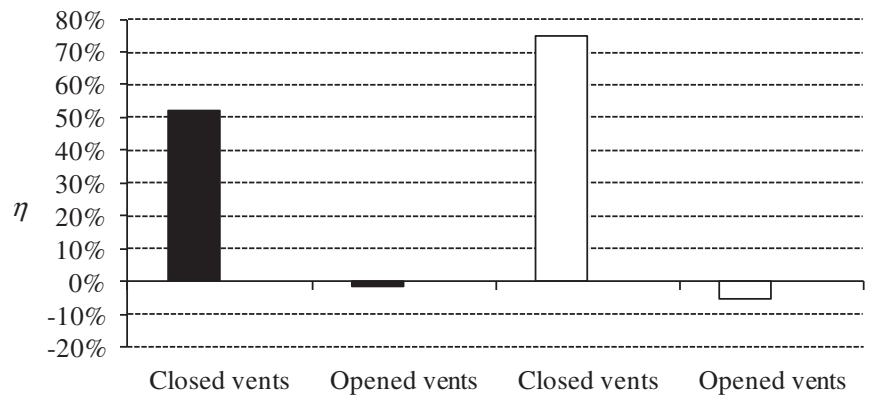

-Energy efficiency index without solar radiation

$\square$ Energy efficiency index with solar radiation

Fig. 11. Energy efficiency index in winter scenario.

the comfort temperature, in the case of a double glazed facade with an $A=30$ air cavity, is calculated. Then, the percentage of saving or increased energy use obtained are calculated compared to the single glazed facade, reference case. For this, the energy efficiency index $(\eta)$ has been defined using the following formula: $\eta=\left(Q-Q_{\text {ref }}\right) /$ $Q_{\text {ref, }}$, where $Q$ the heat flux obtained; and $Q_{\text {ref }}$ the heat flux of reference.

In the winter scenario, the reference heat fluxes are $17.9 \mathrm{~W} / \mathrm{m}^{2}$ and $22 \mathrm{~W} / \mathrm{m}^{2}$ with and without solar radiation respectively. In the summer scenario, the reference heat fluxes are $-10.5 \mathrm{~W} / \mathrm{m}^{2}$ and $-4.6 \mathrm{~W} / \mathrm{m}^{2}$ with and without solar radiation respectively.

The values obtained for winter and summer scenarios are presented in detail in Table 2.

\section{Conclusions}

After analyzing the results obtained from the simulations, the most efficient facade configuration for both scenarios is discussed:

- In the winter scenario, closed vents are always efficient, both with solar radiation and without it, because the average temperature in the enclosure always increases. Of these, the most favorable is always the case in which there is solar radiation. Ventilating is not beneficial in any case, as it lowers the enclosure temperature and increases the transmission losses.

- In the summer scenario, in the absence of solar radiation, closed vents are always efficient, because the average temperature in the enclosure always remains below the reference temperature. In the presence of solar radiation, opened vents are efficient, since they favor the stack effect and the average temperature in the enclosure decreases.

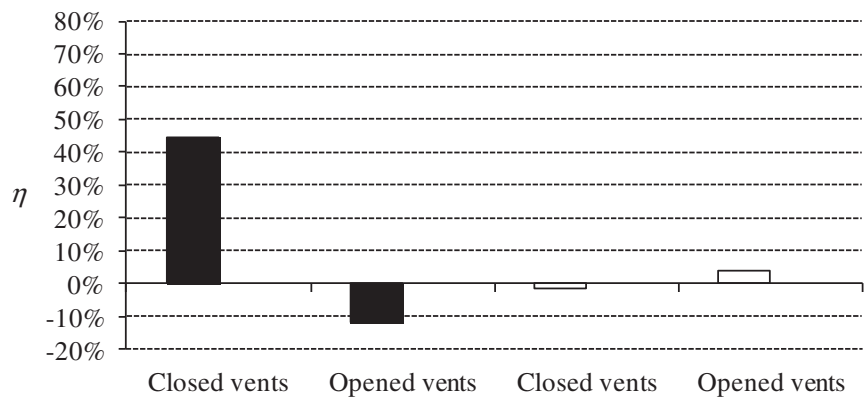

- Energy efficiency index without solar radiation

$\square$ Energy efficiency index with solar radiation

Fig. 12. Energy efficiency index in summer scenario.
Table 2

Percentage of energy saving or increased energy use in winter and summer scenarios compared to the single skin facade.

\begin{tabular}{ccccc}
\hline Scenario & Solar radiation & Vents & Energy saving (\%) & Increased energy use (\%) \\
\hline \multirow{4}{*}{ Winter } & No & $\begin{array}{l}\text { Closed } \\
\text { Opened }\end{array}$ & 52.3 & 1.5 \\
& Yes & $\begin{array}{l}\text { Closed } \\
\text { Opened }\end{array}$ & 75.1 & 5.1 \\
Summer & No & $\begin{array}{l}\text { Closed } \\
\text { Opened } \\
\text { Closed } \\
\text { Opened }\end{array}$ & 44.3 & 12 \\
& Yes & 4 & 1.4 \\
\hline
\end{tabular}

Ventilating lowers the heat transmission gains and, hence, the cooling load.

It can be concluded that the double skin facade is better than the single skin facade in four scenarios: winter with closed vents and with and without solar radiation, summer with closed vents and without solar radiation, and summer with opened vents and with solar radiation. Closing the vents was more energy efficient in three out of four scenarios. Opening the vents is only efficient in summer with solar radiation. The double skin facade reduced the heating load in winter and the cooling load in summer. The worst scenario in winter is opening the vents with solar radiation, because it increases the heating load; and the worst summer scenario is opening the vents without solar radiation because it increases the cooling load.

The historical temperature record in central Spain was consulted in the AEMET database (Spanish State Meteorology Agency) in order to determine whether the double skin facade solution is efficient compared to the single skin facade. It was observed that the heating is used for 5 months, the air-conditioning for 4 months and during 3 months no system is needed. According to the information presented above in Figs. 11 and 12, it is concluded that the double skin facade has better results in terms of saving compared to the single skin facade in winter and summer scenarios. It is particularly noteworthy that the energy saving reach $75 \%$ in the winter scenario with closed vents and with solar radiation; and up to $4 \%$ in the summer scenario with opened vents and with solar radiation.

Double skin facades improve the thermal performance of buildings, they reduce the energy consumption for heating and air conditioning in several scenarios, and they can help produce comfortable indoor conditions. Please note that this paper studies the double skin facade with solely buoyancy-driven airflow. The optimization of vents and the wind-driven airflow will be further studied.

\section{References}

Balocco C. A simple model to study ventilated facades energy performance. Energy Build 2002:34:469-75.

Batchelor GK. Heat transfer by free convection across a closed cavity between vertical boundaries at different temperatures. Q Appl Math 1953;12:209-33.

Eicker U, Fux V, Bauer U, Mei L, Infield D. Façades and summer performance of buildings. Energy Build 2008;40:600-11.

ElSherbiny SM, Raithby GD, Hollands KG. Heat transfer by natural convection across vertical and inclined air layers. J Heat Transf 1982;104:96-102.

EN 410:2011. Vidrio para la edificación. Determinación de las características luminosas y solares de los acristalamientos. Comité Europeo de Normalización (CEN); 2011.

EN 673: 2011. Vidrio en la construcción. Determinación del coeficiente de transmisión térmica (valor U). Método de cálculoComité Europeo de Normalización (CEN); 2011.

EN ISO 10456:2012. Materiales y productos para la edificación. Propiedades higrotérmicas. Valores tabulados de diseño y procedimientos para la determinación de los valores térmicos declarados y de diseño. Comité Europeo de Normalización (CEN); 2012.

Etheridge DW. Nondimensional methods for natural ventilation design. Build Environ 2002;37:1057-72.

Faggembauu D, Costa M, Soria M, Oliva A. Numerical analysis of the thermal behaviour of ventilated glazed facades in Mediterranean climates. Part I: development and validation of a numerical model. Sol Energy 2003;75:217-28.

Fuliotto R, Cambuli F, Mandas N, Bacchin N, Manara G, Chen Q. Experimental and numerical analysis of heat transfer and airflow on an interactive building facade. Energy Build 2010;42:23-8. 
Gratia E, De Herde A. Are energy consumptions decreased with the addition of a doubleskin? Energy Build 2007;39:605-19.

Guía de la herramienta. Passivhaus tool guide, PHPP 7. Passivhaus Institut (PHI); 2012.

He G, Shu L, Zhang S. Double skin facades in the hot summer and cold winter zone in China: cavity open or closed? Build Simul 2011;4:283-91.

Hien WN, Liping W, Chandra AN, Pandey AR, Xiaolin W. Effects of double glazed facade on energy consumption, thermal comfort and condensation for a typical office building in Singapore. Energy Build 2005;37:563-72.

Kim Y-M, Kim S-Y, Shin S-W, Sohn J-Y. Contribution of natural ventilation in a double skin envelope to heating load reduction in winter. Build Environ 2009;44:2236-44.

Korpela SA, Gözüm D, Baxi CB. On the stability of the conduction regime of natural convection in a vertical slot. Int J Heat Mass Transf 1973;16:1683-90.

Lartigue B, Lorente S, Bourret B. Multicellular natural convection in a high aspect ratio cavity: experimental and numerical results. Int J Heat Mass Transf 2000;43:3157-70.

Li R, Pitts A, Li Y. Buoyancy-driven natural ventilation of a room with large openings. Build Simul 2007:984-91.

Manz $\mathrm{H}$. Total solar energy transmittance of glass double façades with free convection. Energy Build 2004;36:127-36.

Pappas A, Zhai Z. Numerical investigation on thermal performance and correlations of double skin façade with buoyancy-driven airflow. Energy Build 2008;40:466-75.
Saelens D, Carmeliet J, Hens H. Energy performance assessment of multiple-skin facades. HVAC\&R Res 2003;9:167-85.

Sanchez E, Rolando A. Ventilation and sealing in the current envelopes in architecture. Constr Build Res. Netherlands: Springer; 2014. p. 103-10.

Wright JL. A correlation to quantify convective heat transfer between vertical window glazings. ASHRAE Trans 1996;102:940-6.

Xamán J, Álvarez G, Lira L, Estrada C. Numerical study of heat transfer by laminar and turbulent natural convection in tall cavities of façade elements. Energy Build 2005; 37:787-94.

Yakhot V, Orzag SA, Thangam S, Gatski TB, Speziak CG. Development of turbulence models for shear flows by a double expansion technique. Phys Fluids 1992;4: 1510-20.

Yin SH, Wung TY, Chen K. Natural convection in an air layer enclosed within rectangular cavities. Int J Heat Mass Transf 1978;21:307-15.

Zerefos SC. On the performance of double skin facades in different environmental conditions. Int J Sustain Energy 2007;26:221-9. 